\title{
Deadbeat Control of a Three-Phase T-type Inverter with Output LC Filter for UPS Applications
}

\author{
Sertac Bayhan $^{1}$, Hasan Komurcugil ${ }^{2}$, and I. Safak Bayram ${ }^{3}$ \\ ${ }^{1}$ Hamad Bin Khalifa University, Qatar Environment and Energy Research Institute, Doha, Qatar \\ ${ }^{2}$ Department of Computer Engineering, Eastern Mediterranean University, Famagusta, Via Mersin 10, Turkey \\ ${ }^{3}$ Department of Electronic and Electrical Engineering, University of Strathclyde, Glasgow, United Kingdom \\ sbayhan@hbku.edu.qa, hasan.komurcugil@emu.edu.tr, safak.bayram@strath.ac.uk
}

\begin{abstract}
In this paper, a deadbeat control technique is presented for a three-phase three-level T-type inverter with an output LC filter for the uninterruptible power supply (UPS) applications. The deadbeat controller is an attractive control solution for many applications where the fast transient response is required. The main idea behind the deadbeat control is to drive the system from any arbitrary initial state to a desired final state infinite number of time steps. Computer simulations investigate the performance of the proposed deadbeat technique for the T-type inverter. It is shown that the output voltage amplitude and frequency are kept constant under various load types, including linear and nonlinear loads. Furthermore, the total harmonic distortion of the output voltage is within the international standards.
\end{abstract}

Index Terms-DC-AC power converters, distributed power generation, stability, unbalanced loads.

\section{INTRODUCTION}

In this modern world, most of the organizations are dependent on the reliable power supply for effective functioning. In particular, it is crucial to run sensitive medical, communication, and information technology (IT) equipment without any interruption in case of the power outage [1]. For that reason, the uninterruptible power supply (UPS) is required in such places to support and protect the critical loads that cannot afford power outage. The primary role of UPS is to provide the voltage that has constant amplitude and frequency to the load without interruption due to power outage in the utility. This specification p rovides e mergency p ower t o a $1 \mathrm{oad} w$ hen the input power source or mains power fails. Furthermore, the total harmonic distortion (THD) of the output voltage should be within the international standards. For that reason, the THD of output voltage and characteristics of transient response identify the performance of UPS.

The core of the UPSs is the voltage source inverter (VSI) that can be in various topologies. Although in many UPS applications, the traditional three-phase two-level VSI is used, the multilevel inverters (MI)s, recently, are employed in UPS applications due to their many advantages. High efficiency, low THD, and small $d v / d t$ are just some of these advantages [2][4]. The MI topologies are based on neutral point clamped (NPC) [4], T-type [5], [6], flying c apacitor ( FC) [ 7], and cascaded H-bridge [8]. The T-type inverter provides better efficiency than other existing MI topologies when it is operated within the medium switching frequency range $(6-30 \mathrm{kHz})$ [9]. For that reason, in this study, the T-type inverter is selected as DC-AC power conversion stage in the UPS.

The control techniques play a critical role so as to ensure voltage regulation of UPSs. There are a number of studies proposed in the literature to regulate the output voltage of the UPSs. Some studies proposed linear control techniques like proportional-integral controllers using pulse-width modulation (PWM) [10]-[12], predictive control [13]-[15], multiloop feedback control [11] and repetitive-based controllers [2], [16]. In most of these control techniques, the cascaded control loop (outer and inner) and the modulation stage are required in order to produce the drive signals for the inverter switches.

As an alternative to the above control techniques, the deadbeat control (DBC) is used in many power electronics applications. It uses a discrete-time model of the system in the computed control law to assure the controlled variable tracks the reference values in the next switching instant [17], [18]. Simplicity is the main advantage of this control technique and, it can be easily run in digital platforms such as microcontrollers, digital signal processors, FPGAs. Apart from this advantage, the DBC technique brings several benefits such as nearly zero steady-state error, minimum rise, and settling time. These advantages make this control technique attractive for power converters. On the other hand, there are some drawbacks to the DBC technique. For example, the mismatches in the system model result in instability, whereas the delay in the digital control leads to oscillations. [19]. Fortunately, fast digital platforms are available today to facilitate the possibility of implementation.

This study mainly focuses on the DBC scheme for a three-phase three-level T-type inverter with output LC filter in UPS applications. The simulation model of the T-type inverter and its control scheme are prepared and simulated in Matlab/Simulink environment. The simulation studies show that the output voltage amplitude and frequency are kept constant under various load types, including linear and nonlinear loads. This paper is divided as follows: in Section II, the mathematical model is presented for the three-phase threelevel T-type inverter connected to the load through the LC filter; in Section III, the DBC is described; in Section IV, the simulation results are presented for the proposed deadbeat 


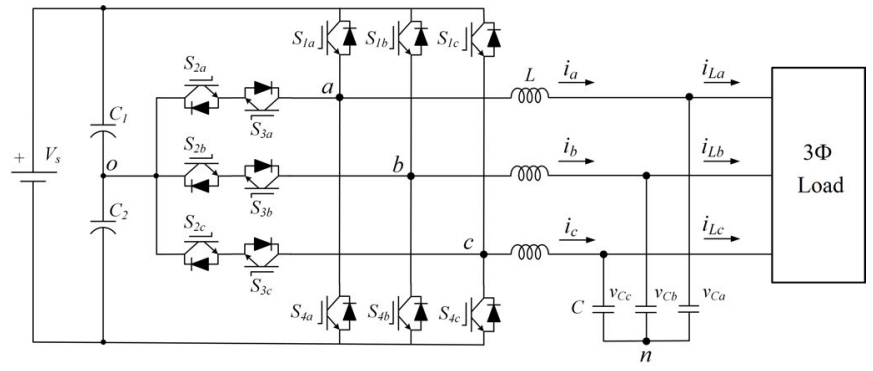

Fig. 1. A three-phase three-level T-type inverter with an LC filter.

controller; finally, in Section $\mathrm{V}$, the conclusions are drawn.

\section{Modeling of T-Type InVerter with LCL Filter}

The schematic diagram of the considered system is shown in Fig. 1, which consists of the three-phase three-level T-type inverter, LC filter, and the input DC source [20]. The phase voltages can be represented by the following space vector

$$
\mathbf{V}=v_{a n}+\mathbf{a} v_{b n}+\mathbf{a}^{2} v_{c n}
$$

where $\mathbf{a}=e^{j 2 \pi / 3}$. As indicated in Fig. 2, there are twenty-seven voltage vectors corresponding to switching states of the T-type inverter.

Each of the phase voltages and currents of the system shown in Fig. 1. can be expressed by the following differential equations.

$$
\left.\begin{array}{l}
v_{x n}=L \frac{d i_{x}}{d t}+v_{C x} \\
i_{x}=C \frac{d v_{C x}}{d t}+i_{L x}
\end{array}\right\}
$$

where $x$ denotes one of the phases $\mathrm{a}, \mathrm{b}$, or $\mathrm{c}$. The space vector of the current (I) is defined as

$$
\mathbf{I}=i_{a}+\mathbf{a} i_{b}+\mathbf{a}^{2} i_{c}
$$

Then, the differential equations in (2) can be expressed as

$$
\left.\begin{array}{l}
\mathbf{V}=L \frac{d \mathbf{I}}{d t}+\mathbf{V}_{C} \\
\mathbf{I}=C \frac{d \mathbf{V}_{C}}{d t}+\mathbf{I}_{L}
\end{array}\right\}
$$

Finally, the differential equations in (4) can be put into the following matrix form

$\frac{d}{d t} \underbrace{\left[\begin{array}{c}\mathbf{V}_{\mathbf{C}} \\ \mathbf{I}\end{array}\right]}_{x}=\underbrace{\left[\begin{array}{cc}0 & \frac{1}{C} \\ -\frac{1}{L} & 0\end{array}\right]}_{F} \underbrace{\left[\begin{array}{c}\mathbf{V}_{\mathbf{C}} \\ \mathbf{I}\end{array}\right]}_{x}+\underbrace{\left[\begin{array}{c}0 \\ \frac{1}{L}\end{array}\right]}_{G} \mathbf{V}+\underbrace{\left[\begin{array}{c}-\frac{1}{C} \\ 0\end{array}\right]}_{H} \mathbf{I}_{(5)}$

Assuming that the inputs $\mathbf{V}$ and $\mathbf{I}_{\mathbf{L}}$ are constant between sampling instants $\mathrm{k} T_{s}$ and $(\mathrm{k}+1) T_{s}$, (5) can be discretized to obtain the discrete-time state equation

$\mathbf{x}(k+1)=e^{F T_{s}} \mathbf{x}(k)+\left(e^{F T_{s}}-\mathbf{U}\right) F^{-1}\left[G \mathbf{V}(k)+H \mathbf{I}_{L}(k)\right]$

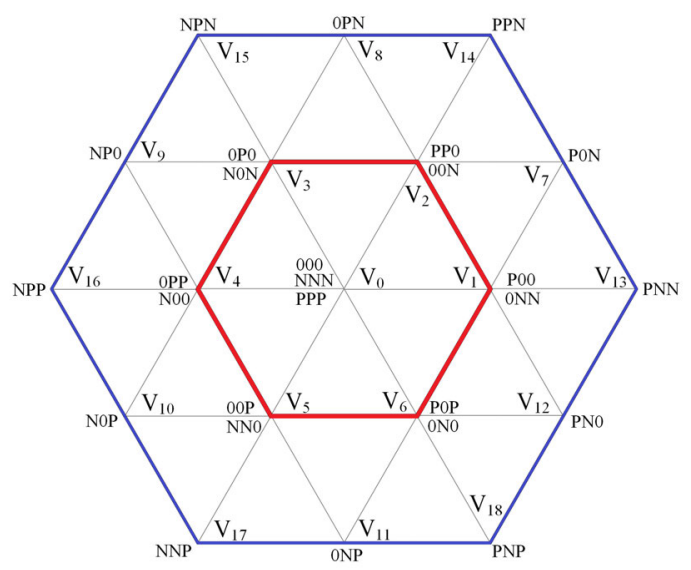

Fig. 2. Voltage vectors of the three-phase three-level T-type inverter.

\section{Deadbeat Control}

The DBC, which is a member of predictive control, is one of the promising control techniques. Similar to other predictive control techniques, the main idea behind the DBC is that it uses the discrete-time model of the considered system to compute the reference modulation signal. To be precise, the actual and reference quantities are evaluated in the discretetime model at the current sampling instant $(k)$ to define the reference modulation signal $u_{r e f}$ at the next sampling instant $(k+1)$. Thus, the actual control parameters are forced to track their references at the end of the next sampling time. More detail about the DBC can be found in [21].

To obtain the DBC law, it is required to extract the mathematical model of the system. The continuous-time mathematical model of the system is represented in (1)-(6). The state equations of the system can be expressed as

$$
x(k+1)=\mathbf{A} x(k)+\mathbf{b} \mathbf{V}(k)+\mathbf{d I}_{L}(k)
$$

where the matrices $\mathbf{A}, \mathbf{b}$ and $\mathbf{d}$ are are respectively defined as

$$
\begin{gathered}
\mathbf{A}=\mathbf{e}^{\mathbf{F} \mathbf{T}_{\mathbf{s}}}=\left[\begin{array}{cc}
\cos \left(\omega_{o} T_{s}\right) & \frac{1}{\omega_{o} C} \sin \left(\omega_{o} T_{s}\right) \\
-\frac{1}{\omega_{o} L} \sin \left(\omega_{o} T_{s}\right) & \cos \left(\omega_{o} T_{s}\right)
\end{array}\right] \\
\mathbf{b}=\left(\mathbf{e}^{\mathbf{F} \mathbf{T}_{\mathbf{s}}}-\mathbf{U}\right) \mathbf{F}^{-\mathbf{1}} \mathbf{G}=\left[\begin{array}{c}
1-\cos \left(\omega_{o} T_{s}\right) \\
\frac{1}{\omega_{o} L} \sin \left(\omega_{o} T_{s}\right)
\end{array}\right] \\
\mathbf{\mathbf { I } _ { \mathbf { L } }} \\
\mathbf{d}=\left(\mathbf{e}^{\mathbf{F} \mathbf{T}_{\mathbf{s}}}-\mathbf{U}\right) \mathbf{F}^{-\mathbf{1}} \mathbf{H}=\left[\begin{array}{c}
-\frac{1}{\omega_{o} C} \sin \left(\omega_{o} T_{s}\right) \\
1-\cos \left(\omega_{o} T_{s}\right)
\end{array}\right]
\end{gathered}
$$
where $\omega_{o}$ is angular frequency. Now, let's define control law as

$$
\left.\begin{array}{l}
\mathbf{x}(k)=\mathbf{x}^{*}(k)+\Delta \mathbf{x}(k) \\
\mathbf{V}(k)=\mathbf{V}^{*}(k)+\Delta \mathbf{V}(k)
\end{array}\right\}
$$

where $\mathrm{x}^{*}(\mathrm{k})$ denotes reference state vector and $\mathbf{V}^{*}(\mathrm{k})$ denotes reference voltage vector at the kth sampling instant. Substituting (8) in (7) gives

where $\mathbf{U}$ is the $2 \times 2$ unit vector and $T_{s}$ is the sampling time. 


$$
\begin{aligned}
\mathbf{x}^{*}(k+1)+\Delta \mathbf{x}(k+1)= & \mathbf{A} \mathbf{x}^{*}(k)+\mathbf{A} \Delta \mathbf{x}(k) \\
& +\mathbf{b}\left(\mathbf{V}^{*}(k)+\Delta \mathbf{V}(k)\right)
\end{aligned}
$$

with the definitions in (8) and (9), we have

$$
\Delta \mathbf{x}(k+1)=\mathbf{A} \Delta \mathbf{x}(k)+\mathbf{b} \Delta \mathbf{V}(k)+d \mathbf{I}_{\mathbf{L}}(k) .
$$

The control law can now be expressed as

$$
\Delta \mathbf{V}(k)=-K \Delta \mathbf{x}(k)+\Delta \mathbf{V}^{l}(k)
$$

The closed-loop system state equation can then be expressed as

$$
\Delta \mathbf{x}(k+1)=A_{c} \Delta \mathbf{x}(k)+\mathbf{b} \Delta \mathbf{V}^{l}(k)+d \mathbf{I}_{\mathbf{L}}(k) .
$$

Then, this closed-loop system state equation at the next step $(k+2)$ can be written as

$$
\Delta \mathbf{x}(k+2)=A_{c} \Delta \mathbf{x}(k+1)+\mathbf{b} \Delta \mathbf{V}^{l}(k+1)+d \mathbf{I}_{\mathbf{L}}(k+1) .
$$

Substituting (12) in (13) gives

$$
\begin{aligned}
\Delta \mathbf{x}(k+2)= & A_{c} \mathbf{b} \Delta \mathbf{V}^{l}(k)+A_{c} \mathbf{d} \mathbf{I}_{L}(k) \\
& +\mathbf{b} \Delta \mathbf{V}^{l}(k+1)+d \mathbf{I}_{\mathbf{L}}(k+1) .
\end{aligned}
$$

where

$$
\begin{aligned}
& A_{c} \mathbf{b}=\left[\begin{array}{c}
2 \sin ^{2}\left(\frac{\theta_{s}}{2}\right) \\
-\frac{1}{X_{L}} \sin \left(\theta_{s}\right)
\end{array}\right]=\left[\begin{array}{c}
b_{1} \\
-b_{2}
\end{array}\right] \\
& A_{c} \mathbf{d}=\left[\begin{array}{c}
-X_{C} \tan \left(\frac{\theta_{s}}{2}\right) \cos \left(\theta_{s}\right) \\
\cos \left(\theta_{s}\right)
\end{array}\right]
\end{aligned}
$$

In (14) the fact that $A_{c}^{2}=0$ is used and in (15), $X_{C}=\frac{1}{\omega_{o} C}$ and $\theta_{s}=\omega_{o} T_{s}$. For DBC, the change in the capacitor voltage $\Delta \mathbf{V}_{\mathbf{C}}$ needs to be zero. Substituting (14) in (15), the $\Delta \mathbf{V}_{\mathbf{C}}$ at $(k+2)$ instant can be expressed as

$$
\begin{aligned}
\Delta \mathbf{V}_{C}(k+2) & =b_{1}\left(\Delta \mathbf{V}^{l}(k)+\Delta \mathbf{V}^{l}(k+1)\right) \\
& +\left(-X_{C} \tan \left(\frac{\theta_{s}}{2}\right) \cos \left(\theta_{s}\right)\right) \mathbf{I}_{L}(k) \\
& -\left(X_{C} \sin \left(\theta_{s}\right)\right) \mathbf{I}_{L}(k+1)=0
\end{aligned}
$$

The correction term in the manipulated inverter voltage vector is thus updated according to

$$
\begin{aligned}
\Delta \mathbf{V}^{l}(k+1)= & -\Delta \mathbf{V}^{l}(k)+\left(X_{C} \cot \left(\theta_{s}\right)\right) \mathbf{I}_{L}(k) \\
& +\left(X_{C} \cot \left(\frac{\theta_{s}}{2}\right)\right) \mathbf{I}_{L}(k+1)
\end{aligned}
$$

The implementation of the control law in (11) requires the evaluation of the inverter voltage vector reference $\left(\mathbf{V}^{*}(\mathrm{k})\right)$. First, the reference of the capacitor voltage vector $\mathbf{V}_{\mathbf{C}}^{*}$ should be specified by (18) since it is the controlled variable. After that the inverter reference voltage vector $\mathbf{V}^{*}$ and inverter reference current vector $\mathbf{I}^{*}$ can be obtained through Eqn. (7) [21]. For sinusoidal variations

$$
\begin{aligned}
\mathbf{V}_{\mathbf{C}}^{*}(k+1) & =V_{c r} e^{j(k+1) \omega T_{s}}=e^{j \omega T_{s}} \mathbf{V}_{\mathbf{C}}^{*}(k) \\
& =q \mathbf{V}_{\mathbf{C}}^{*}(k) \\
\mathbf{I}^{*}(k+1) & =q \mathbf{I}^{*}(k)
\end{aligned}
$$

Substituting (18) in (7) and solving yields

$$
\left.\begin{array}{l}
\mathbf{V}^{*}(k)=\mathbf{V}_{C}^{*}(k) \frac{q^{2}-2 a q+1}{(1-a)(1+q)} \\
\mathbf{I}^{*}(k)=\mathbf{V}_{C}^{*}(k) \frac{b_{2}(q-1)}{(1-a)(1+q)}
\end{array}\right\}
$$

\section{RESUlTS}

In this section, the performance of the LC-filtered threephase three-level T-type inverter shown in Fig. 3 under various operating conditions is investigated. Furthermore, a threephase nonlinear load structure shown in Fig. 3 was used to verify the steady-state behavior of the proposed system. Simulations have been carried out by using MATLAB/Simulink software. The values of the system parameters utilized in the simulations are given in Table I.

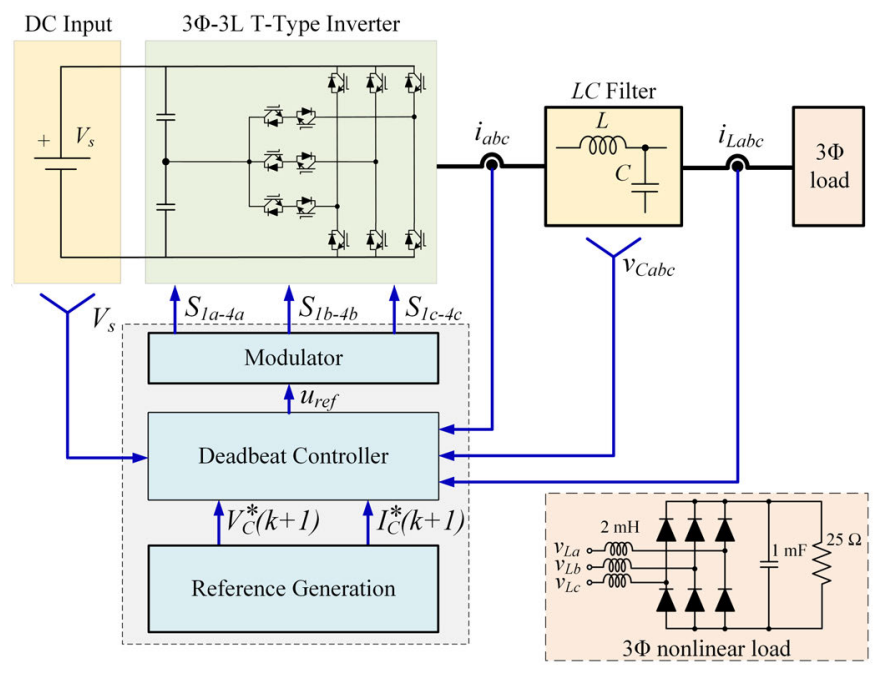

Fig. 3. The block diagram of the simplified control structure of the threephase three-level T-type inverter in the UPS application.

TABLE I

SYSTEM PARAMETERS

\begin{tabular}{ll}
\hline \hline Parameter & Value \\
\hline Nominal voltage $\left(V_{o}\right)$ & $230 V_{r m s}$ \\
Nominal frequency $\left(\omega_{o}\right)$ & $314 \mathrm{rad} / \mathrm{s}$ \\
Input DC voltage $\left(V_{s}\right)$ & $1000 \mathrm{~V}$ \\
Filter inductance $(L)$ & $3.0 \mathrm{mH}$ \\
Filter resistance $(r)$ & $0.1 \Omega$ \\
Filter capacitor $(C)$ & $22 \mu \mathrm{F}$ \\
DC capacitors $\left(C_{1}\right.$ and $\left.C_{2}\right)$ & $1000 \mu \mathrm{F}$ \\
Sampling time $\left(T_{s}\right)$ & $40 \mu \mathrm{s}$ \\
\hline \hline
\end{tabular}

Fig. 4 shows the steady-state results of the system with various load conditions. First, three-phase pure resistive load $\left(P_{L}=30 \mathrm{~kW}\right)$ was connected at the output of the UPS and, the results are given in Fig. 4 (a). It can be seen that the output voltage is an almost pure sine wave, and the DC-link capacitor voltages $\left(V_{C 1}\right.$ and $\left.V_{C 2}\right)$ are kept constant under the resistive load.

Second, three-phase resistive load $\left(P_{L}=30 \mathrm{~kW}\right)$, and inductive load $\left(Q_{L}=10 \mathrm{kVar}\right)$ were connected at the output of the UPS and the results are given in Fig. 4 (b). Similarly to the 


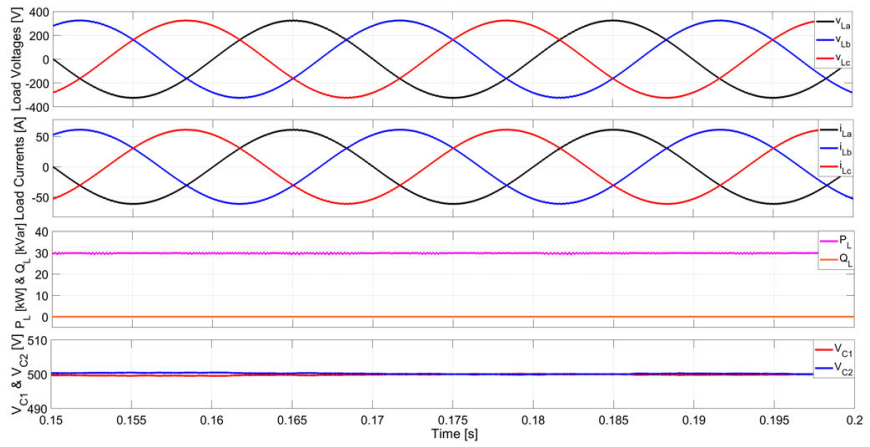

(a)

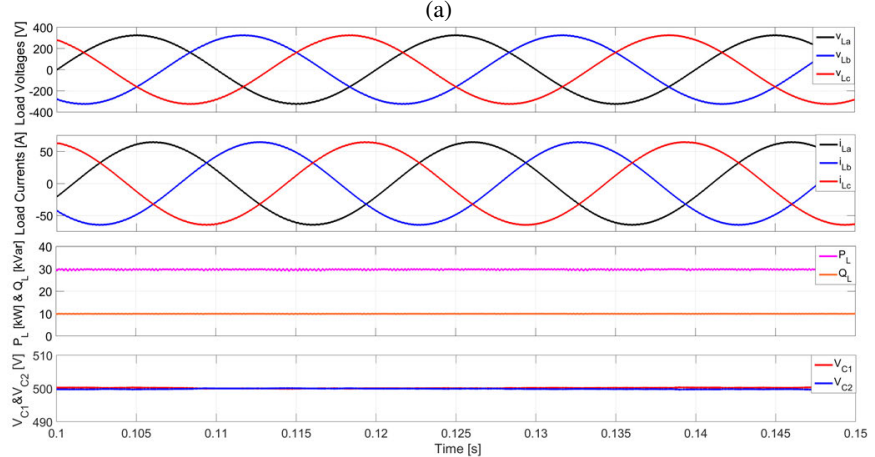

(b)

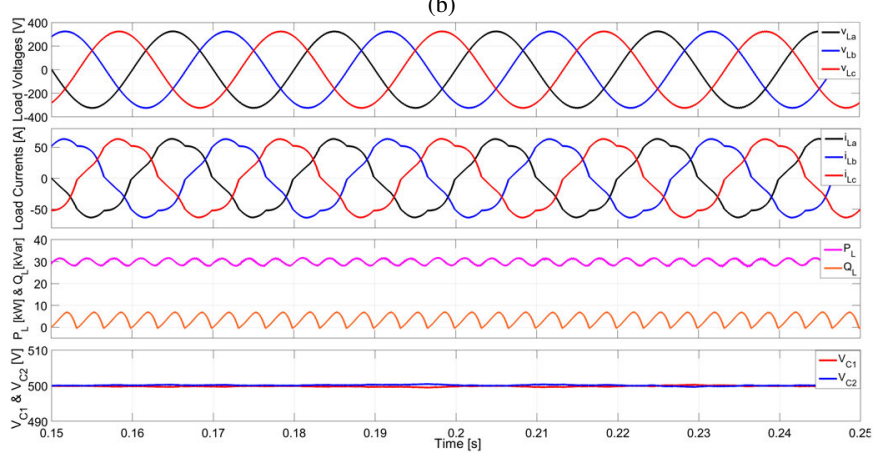

(c)

Fig. 4. Steady-state results; (a) three-phase $R$ load $\left(P_{L}=30 \mathrm{~kW}\right)$, (b) threephase $R L$ load $\left(P_{L}=30 \mathrm{~kW}, Q_{L}=10 \mathrm{kVar}\right)$, (c) three-phase $R$ load $\left(P_{L}=20\right.$ $\mathrm{kW})+$ non-linear load shown in Fig. 3 .

previous case, the output voltage is an almost pure sine wave and the DC-link capacitor voltages $\left(V_{C 1}\right.$ and $\left.V_{C 2}\right)$ are kept constant under the resistive + inductive load.

The impact of nonlinear load was also tested to verify the performance of the system. In this case, three-phase resistive load $\left(P_{L}=20 \mathrm{~kW}\right)$ and the non-linear load shown in Fig. 3 were connected at the output of the UPS and the results are given in Fig. 4 (c). It is clear that the output voltage is still an almost pure sine wave even under the non-linear load condition. There is a ripple on the active and reactive power due to the nonlinear characteristic load. To sum up, the proposed system shows satisfactory performance under the various load types.

Fig. 5 (a) and (b) shows the THD results with respect to Fig. 4(b) and Fig. 4(c), respectively. The output voltage THD level is $0.45 \%$ under the linear load condition whereas it is $0.52 \%$ under the nonlinear load condition. It is clear that the output voltage THD level is within the international standards even under the non-linear load condition.

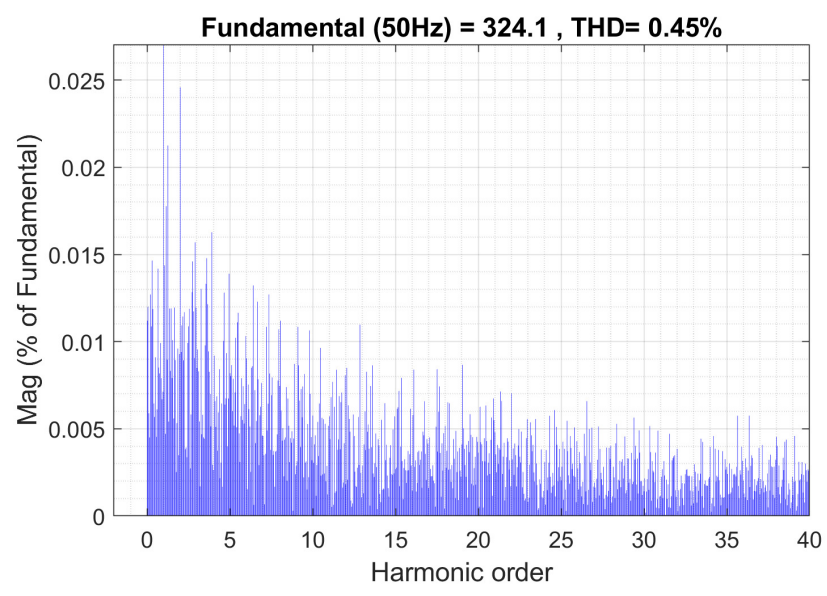

(a)

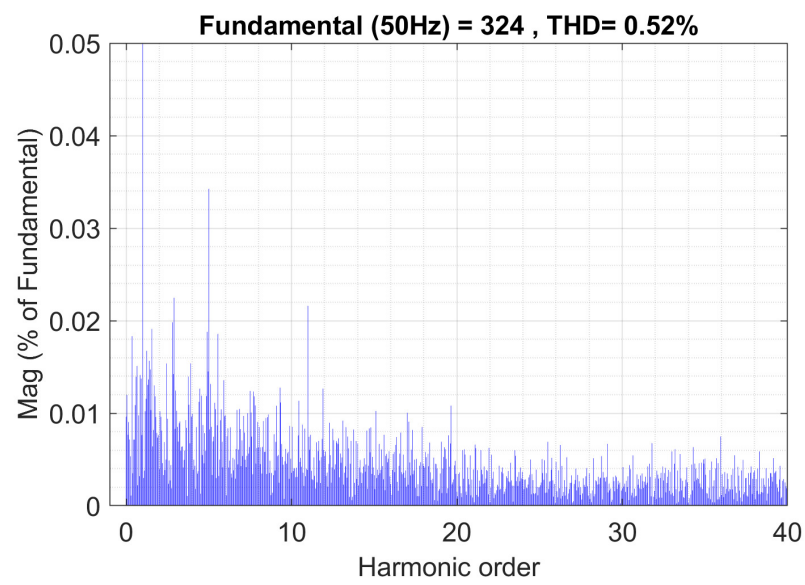

(b)

Fig. 5. Total harmonic distortion (THD) results of the load phase voltage; (a) linear load results with respect to Fig. 4(b); (b) nonlinear load results with respect to Fig. 4(c).

Fig. 6 shows the transient response results of the system with various load conditions. First, three-phase resistive load $\left(P_{L}=25 \mathrm{~kW}\right)$ was connected at the output of the UPS, and the output load was increased to $P_{L}=50 \mathrm{~kW}$ at $\mathrm{t}=0.1 \mathrm{~s}$. The results in this load condition are presented in Fig. 6 (a). It can be seen that transient response is very fast, and no overshoot is observed on the voltage signals. Furthermore, it is shown that the DC-link capacitor voltages $\left(V_{C 1}\right.$ and $\left.V_{C 2}\right)$ are kept constant under the resistive load step change.

In the second case, to observe the effect of the inductive load impact on the transient response, the system also tested under the inductive load condition. At the beginning, there was three-phase resistive load $\left(P_{L}=10 \mathrm{~kW}\right)$ connected at the output of the UPS. At $\mathrm{t}=0.1 \mathrm{~s}$, the output load was increased to $P_{L}=30 \mathrm{~kW}$ and $Q_{L}=10 \mathrm{kVar}$ inductive load was added. It can be seen that transient response is very fast and smooth, and no overshoot is observed on the voltage signals.

Furthermore, the system was tested from no-load to threephase $R$ load $\left(P_{L}=20 \mathrm{~kW}\right)$. In this case, at the beginning, there was no-load at the output of the UPS. At $\mathrm{t}=0.1 \mathrm{~s}$, three-phase load $P_{L}=20 \mathrm{~kW}$ was connected to the output of the UPS. It is clear that the output voltage is kept constant even under 


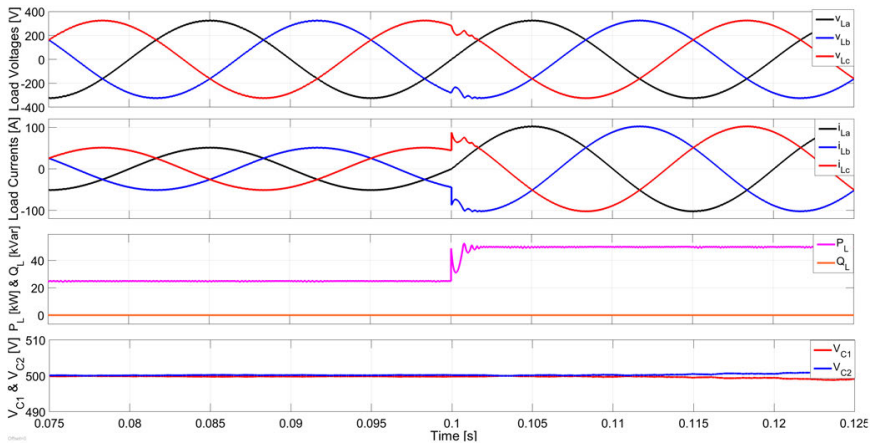

(a)

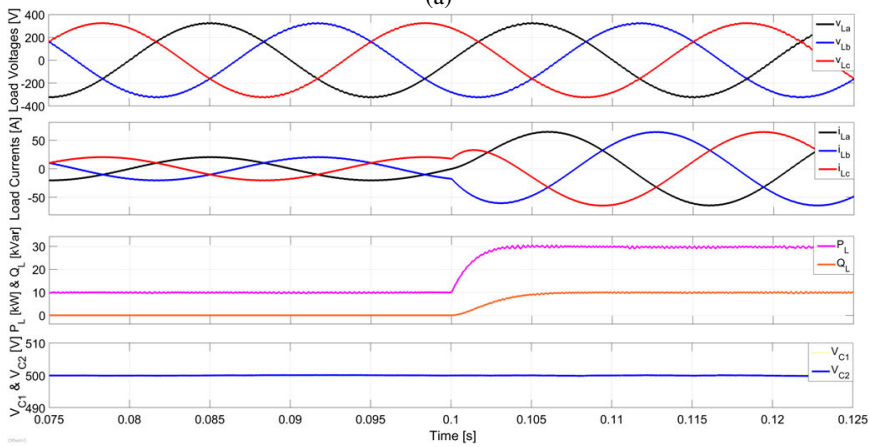

(b)

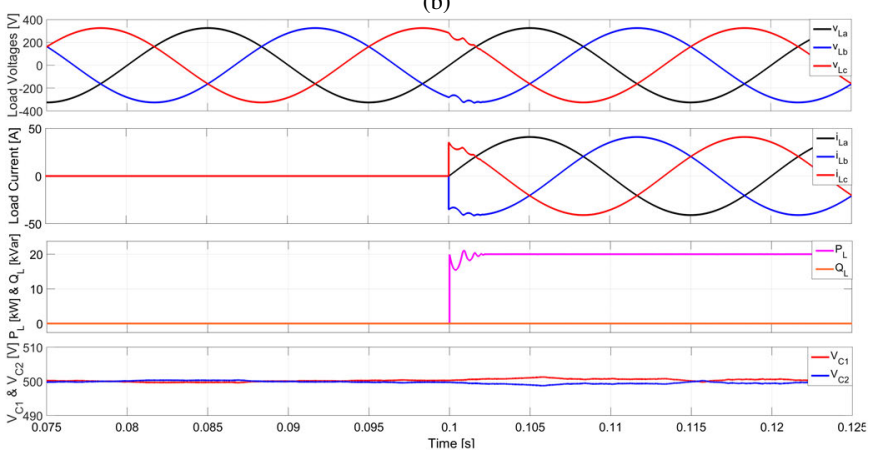

(c)

Fig. 6. Transient response results; (a) three-phase $R$ load from $P_{L}=25$ to $P_{L}=50 \mathrm{~kW}$, (b) three-phase $R$ load $\left(P_{L}=10 \mathrm{~kW}\right)$ from to three-phase $R L$ load $\left(P_{L}=30 \mathrm{~kW}+Q_{L}=10 \mathrm{kVar}\right)$, (c) no load to three-phase $R$ load $\left(P_{L}=20\right.$ $\mathrm{kW})$.

the no-load condition. The transient response is very fast and smooth, and no overshoot is observed on the voltage signals when the load is activated at $\mathrm{t}=0.1 \mathrm{~s}$. Furthermore, it is shown that the DC-link capacitor voltages $\left(V_{C 1}\right.$ and $\left.V_{C 2}\right)$ are kept constant under this condition.

\section{CONCLUSION}

Uninterruptible power supplies play a crucial role when there are critical loads such as medical, communication, and IT equipment. The main aim of UPSs is to generate sinusoidal voltage waveform with constant amplitude and frequency for various load conditions. For that reason, the control techniques for UPSs need to fulfill these requirements. This study presents DBC technique for UPS application due to DBC technique's several advantages such as fast response, nearly zero steadystate error, and easy implementation. The performance of the implemented DBC technique for T-type based UPS is investigated by simulations. It is shown that the output voltage amplitude and frequency is kept constant under various load types including, linear and non-linear loads.

\section{ACKNOWLEDGMENT}

This publication was made possible by NPRP12S-0214190083 from the Qatar National Research Fund (a member of Qatar Foundation). The statements made herein are solely the responsibility of the authors.

\section{REFERENCES}

[1] S. Bayhan, S. S. Seyedalipour, H. Komurcugil, and H. Abu-Rub, "Lyapunov energy function based control method for three-phase ups inverters with output voltage feedback loops," IEEE Access, vol. 7, pp. 113699-113711, 2019.

[2] T. P. Mouselinos and E. C. Tatakis, "Multilevel inverters: A survey of limitations and recommended problem-solving techniques," in 201921 st European Conference on Power Electronics and Applications (EPE'19 ECCE Europe), Sep. 2019, pp. P.1-P.10.

[3] F. L. Tofoli, D. De Andrade Tavares, and J. I. De Assis Saldanha, "Survey on topologies based on the three-state and multi-state switching cells," IET Power Electronics, vol. 12, no. 5, pp. 967-982, 2019.

[4] H. Akagi, "Multilevel converters: Fundamental circuits and systems," Proceedings of the IEEE, vol. 105, no. 11, pp. 2048-2065, Nov 2017.

[5] C. Roncero-Clemente, E. Romero-Cadaval, M. Ruiz-Cortes, and O. Husev, "Carrier level-shifted based control method for the pwm 31-t-type qzs inverter with capacitor imbalance compensation," IEEE Transactions on Industrial Electronics, vol. 65, no. 10, pp. 8297-8306, Oct 2018.

[6] C. Qin, C. Zhang, X. Xing, X. Li, A. Chen, and G. Zhang, "Simultaneous common-mode voltage reduction and neutral-point voltage balance scheme for the quasi-z-source three-level t-type inverter," IEEE Transactions on Industrial Electronics, vol. 67, no. 3, pp. 1956-1967, March 2020.

[7] G. A. Saccol, J. C. Giacomini, A. L. Batschauer, and C. Rech, "Comprehensive analysis of single-phase full-bridge asymmetrical flying capacitor inverters," IEEE Transactions on Industry Applications, vol. 55, no. 2, pp. 1775-1786, March 2019.

[8] S. K. Sahoo and T. Bhattacharya, "Phase-shifted carrier-based synchronized sinusoidal pwm techniques for a cascaded h-bridge multilevel inverter," IEEE Transactions on Power Electronics, vol. 33, no. 1, pp. 513-524, Jan 2018.

[9] Z. Wang, Y. Wu, M. H. Mahmud, Z. Zhao, Y. Zhao, and H. A. Mantooth, "Design and validation of a $250-\mathrm{kw}$ all-silicon carbide high-density three-level t-type inverter," IEEE Journal of Emerging and Selected Topics in Power Electronics, vol. 8, no. 1, pp. 578-588, March 2020

[10] S. Bayhan, H. Abu-Rub, J. I. Leon, S. Vazquez, and L. G. Franquelo, "Power electronic converters and control techniques in ac microgrids," in IECON 2017 - 43rd Annual Conference of the IEEE Industrial Electronics Society, 2017, pp. 6179-6186.

[11] J. S. Lim, C. Park, J. Han, and Y. I. Lee, "Robust tracking control of a three-phase dcac inverter for ups applications," IEEE Transactions on Industrial Electronics, vol. 61, no. 8, pp. 4142-4151, Aug 2014.

[12] S. Bayhan and H. Abu-Rub, "A simple control technique for distributed generations in grid-connected and islanded modes," in 2018 IEEE 27th International Symposium on Industrial Electronics (ISIE), June 2018, pp. 1237-1242.

[13] P. Cortes, G. Ortiz, J. I. Yuz, J. Rodriguez, S. Vazquez, and L. G. Franquelo, "Model predictive control of an inverter with output $l c$ filter for ups applications," IEEE Transactions on Industrial Electronics, vol. 56, no. 6, pp. 1875-1883, June 2009.

[14] S. Bayhan, M. Trabelsi, H. Abu-Rub, and M. Malinowski, "Finitecontrol-set model-predictive control for a quasi-z-source four-leg inverter under unbalanced load condition," IEEE Transactions on Industrial Electronics, vol. 64, no. 4, pp. 2560-2569, 2017.

[15] M. Sarbanzadeh, M. A. Hosseinzadeh, E. Sarebanzadeh, and M. Rivera, "Recent predictive control strategies applied to flying capacitor multilevel inverters," in 2018 IEEE International Conference on Automation/XXIII Congress of the Chilean Association of Automatic Control (ICA-ACCA), Oct 2018, pp. 1-6.

[16] A. Lidozzi, C. Ji, L. Solero, P. Zanchetta, and F. Crescimbini, "Digital deadbeat and repetitive combined control for a stand-alone four-leg vsi," IEEE Transactions on Industry Applications, vol. 53, no. 6, pp. 56245633, Nov 2017. 
[17] O. Kukrer and H. Komurcugil, "Deadbeat control method for singlephase ups inverters with compensation of computation delay," IEE Proceedings - Electric Power Applications, vol. 146, no. 1, pp. 123 128, Jan 1999.

[18] P. Mattavelli, "An improved deadbeat control for ups using disturbance observers," IEEE Transactions on Industrial Electronics, vol. 52, no. 1, pp. 206-212, Feb 2005.

[19] G. Du, J. Li, F. Du, and Z. Liu, "A robust digital control strategy using error correction based on the discrete lyapunov theorem," Energies, vol. 11, p. 848, 2018.

[20] H. Komurcugil and S. Bayhan, "Sliding mode control strategy for threephase three-level t-type pwm rectifiers with capacitor voltage imbalance compensation," in IECON 2019 - 45th Annual Conference of the IEEE Industrial Electronics Society, vol. 1, Oct 2019, pp. 3571-3576.

[21] O. Kukrer, "Deadbeat control of a three-phase inverter with an output lc filter," IEEE Transactions on Power Electronics, vol. 11, no. 1, pp. 16-23, Jan 1996. 